\title{
FAKTOR-FAKTOR YANG BERHUBUNGAN DENGAN KEJADIAN GIZI KURANG PADA BALITA DI POSYANDU DESA GALUDRA KECAMATAN PONDOK SALAM KABUPATEN PUWAKARTA
}

\author{
Cik Angkut ${ }^{*}$ \\ ${ }^{1}$ Sekolah Tinggi IImu Kesehatan Prima Indonesia Bekasi \\ Email: cikyoes@gmail.com
}

\begin{abstract}
Nutrition is one of the important factors that determine the level of health and harmony between physical development and mental development. Most mothers have children with good nutrition, $96.7 \%$ of respondents. The purpose of this study was to determine the relationship between age, education, occupation, parity, food intake, parity, infectious diseases, bedroom conditions, cigarette smoke environment, and socio-economic with the incidence of malnutrition in children under five in Posyandu Galudra Village, Pondok Salam District Purwakarta Regency. The research design was analytical with cross-sectional method. The study was conducted at the Posyandu in Galudra Village, Pondok Salam Subdistrict, Purwakarta Regency. The population of underfives was 200 people, the study sample was toddlers as many as 61 people. The independent variables are age, education, occupation, parity, food intake, parity, infectious disease, bedroom conditions, cigarette smoke environment, and socio-economic and dependent variable malnutrition in children under five. Data was collected through filling out questionnaires, processed and analyzed with statistical tests with SPSS 16.0 program with $p$ value $=0.05$. The results showed that from 61 respondents (82\%) respondents aged 17-34 years, $(85.2 \%)$ respondents had a low education level (junior high and lower), (77\%) respondents did not work, (98.4\%) respondents who work have low parity, $(62.3 \%)$ toddlers have less food intake, $(62.3 \%)$ respondents have less diet, (57.4\%) respondents have infectious diseases, (78.7\%) respondents have the condition of the bedroom is good, $(80.3 \%)$ respondents have a cigarette smoke environment, $(60.7 \%)$ respondents have less income. Poor nutrition incidence is not related to maternal age ( $\rho$ value $=0.068)$, is related to maternal education ( $\rho$ value $=$ $0.001)$, is related to maternal employment ( $\rho$ value $=0.001)$, is related to maternal parity $(\rho$ value $=0.001)$, none relationship with toddler food intake ( $\rho$ value $=0.142$ ), there is no relationship with toddler eating patterns ( $\rho$ value $=0.142)$, there is a relationship with the condition of the bedroom ( $\rho$ value $=0.017)$, there is a relationship with the cigarette smoke environment ( $\rho$ value $=0.001)$, there is a relationship with socio-economic $(\rho$ value $=0.001$ ). The conclusions in this study are that most toddler nutrition is good.
\end{abstract}

Keywords: toddler nutrition

\section{ABSTRAK}

Gizi merupakan salah satu faktor penting yang menentukan tingkat kesehatan dan keserasian antara perkembangan fisik dan perkembangan mental. Sebagian besar ibu memiliki balita dengan gizi baik sebesar $96,7 \%$ responden. Tujuan penelitian ini untuk mengetahui adanya hubungan antara umur, pendidikan, pekerjaan, paritas, asupan makanan, paritas, penyakit infeksi, kondisi kamar tidur, lingkungan asap rokok, dan sosial ekonomi dengan kejadian gizi kurang pada balita di Posyandu Desa Galudra Kecamatan Pondok Salam Kabupaten Purwakarta. Desain penelitian ini analitik dengan metode cross-sectional. Penelitian dilakukan di Posyandu Desa Galudra Kecamatan Pondok Salam Kabupaten Purwakarta.Populasinya balita sebanyak 200 orang, sampel penelitiannya adalah balita sebanyak 61 orang. Variabel independent umur, pendidikan, pekerjaan, paritas, asupan makanan, paritas, penyakit infeksi, kondisi kamar tidur, lingkungan asap rokok, dan social ekonomi dan variabel dependent gizi kurang pada balita. Data dikumpulkan melalui pengisian kuesioner, diolah dan di analisis dengan uji statistik dengan program SPSS 16.0 dengan $p$ value $=0,05$. Hasil penelitian menunjukkan bahwa dari 61 responden didapatkan $(82 \%)$ responden berumur $17-34$ th, $(85,2 \%)$ responden memiliki tingkat pendidikan rendah (SMP ke bawah), $(77 \%)$ responden tidak bekerja, $(98,4 \%)$ responden yang bekerja memiliki paritas rendah, $(62,3 \%)$ balita memiliki asupan makanan kurang, $(62,3 \%)$ responden memiliki pola makan kurang, $(57,4 \%)$ responden memiliki penyakit infeksi, $(78,7 \%)$ responden memiliki kondisi kamar tidur baik, $(80,3 \%)$ responden memiliki lingkungan asap rokok, $(60,7 \%)$ responden memiliki penghasilan kurang. 
Kejadian gizi kurang tidak berhubungan dengan umur ibu ( $\rho$ value $=0,068)$, berhubungan dengan pendidikan ibu ( $\rho$ value $=0,001$ ), berhubungan dengan pekerjaan ibu ( $\rho$ value $=0,001)$, berhubungan dengan paritas ibu ( $\rho$ value $=0,001$ ), tidak ada hubungan dengan asupan makanan balita ( $\rho$ value $=0,142$ ), tidak ada hubungan dengan pola makan balita ( $\rho$ value $=0,142$ ), ada hubungan dengan kondisi kamar tidur ( $\rho$ value $=0,017$ ), ada hubungan dengan lingkungan asap rokok ( $\rho$ value $=0,001$ ), ada hubungan dengan social ekonomi $(\rho$ value $=$ $0,001)$. Simpulan dalam penelitian ini yaitu sebagian besar gizi balita baik.

Kata kunci : gizi balita

\section{PENDAHULUAN}

Gizi merupakan salah satu faktor penting yang menentukan tingkat kesehatan dan keserasian antara perkembangan fisik dan perkembangan mental. Tingkat keadaan gizi normal tercapai bila kebutuhan zat gizi optimal terpenuhi. Tingkat gizi seseorang dalam suatu masa bukan saja ditentukan oleh konsumsi zat gizi pada masa lampau, bahkan jauh sebelum masa itu (Budiyanto, 2002)

Penelitian ini bertujuan untuk mengetahui factor-faktor yang berhubungan dengan kejadian gizi kurang pada balita berdasarkan factor umur, pendidikan orang tua, pekerjaan orang tua, paritas, asupan makanan, pola makan, penyakit infeksi, kondisi kamar tidur, lingkungan asap rokok, penghasilan di di wilayah Desa Galudra Kecamatan Pondok Salam Kabupaten Purwakarta.

\section{METODOLOGI PENELITIAN}

Jenis penelitian yang dilakukan adalah penelitian deskriptif korelasi yaitu pencarian hubungan antara satu keadaan dengan keadaan lain yang terdapat dalam satu populasi yang sama.Dilaksanakan di wilayah Desa Galudra Kecamatan Pondok Salam Kabupaten Purwakartai pada bulan Agustus-September tahun 2013. Populasi dalam penelitian ini berjumlah 72 balita. Teknik pengambilan sampelnya yaitu secara acak atau random yang disebut dengan teknik random sampling.Sample yang diambil sebanyak 61 balita. Pengumpulan data dilakukan dengan menggunakan data primer yang diperoleh melalui kuisioner. Analisis ini dilakukan terhadap dua variabel yang berhubungan atau berkorelasi. Analisis ini dilakukan dengan uji Chi-square dengan interpretasi hasil $\rho$ value $<0,05$ sehingga Ho ditolak.

\section{HASIL PENELITIAN}

Tabel 1 Hubungan Kejadian Gizi Kurang pada Balita dengan beberapa varibel di Desa Galudra Kecamatan Pondok Salam Kabupaten Purwakarta Tahun 2013

\begin{tabular}{|c|c|c|c|c|c|c|c|}
\hline \multirow{3}{*}{ Umur } & \multicolumn{4}{|c|}{ Status Gizi } & \multirow{2}{*}{\multicolumn{2}{|c|}{ Jumlah }} & \multirow{3}{*}{$\rho$ value } \\
\hline & \multicolumn{2}{|c|}{ Gizi Baik } & \multicolumn{2}{|c|}{ Gizi Kurang } & & & \\
\hline & $\mathrm{n}$ & $\%$ & $n$ & $\%$ & $n$ & $\%$ & \\
\hline $17-34$ th & 49 & 80,32 & 1 & 1,64 & 50 & 81,96 & \multirow{2}{*}{0,068} \\
\hline$>34$ th & 10 & 16,4 & 1 & 1,64 & 11 & 18,04 & \\
\hline Total & 59 & 96,72 & 2 & 3,28 & 61 & 100 & \\
\hline
\end{tabular}

Dari hasil uji statistik antara status gizi dengan umur ibu diperoleh $\rho$ value $=0,068(\rho>a$ $0,05)$, maka dapat disimpulkan bahwa tidak ada hubungan antara umur ibu dengan kejadian gizi kurang pada balita.
Dari hasil uji statistik antara status gizi dengan pendidikan ibu diperoleh $\rho$ value $=0,001$ ( $\rho$ $<$ a 0,05), maka dapat disimpulkan bahwa ada hubungan antara pendidikan ibu dengan kejadian gizi kurang pada balita.

\begin{tabular}{|c|c|c|c|c|c|c|c|}
\hline \multirow{3}{*}{ Pendidikan } & \multicolumn{4}{|c|}{ Status Gizi } & \multirow{2}{*}{\multicolumn{2}{|c|}{ Jumlah }} & \multirow{3}{*}{$\rho$ value } \\
\hline & \multicolumn{2}{|c|}{ Gizi Baik } & \multicolumn{2}{|c|}{ Gizi Kurang } & & & \\
\hline & $\mathrm{n}$ & $\%$ & $\mathrm{n}$ & $\%$ & $\mathrm{n}$ & $\%$ & \\
\hline Tinggi & 9 & 14,75 & 0 & 0 & 9 & 14,75 & \\
\hline Rendah & 50 & 81,96 & 2 & 3,29 & 52 & 85,25 & 0,001 \\
\hline Total & 59 & 96,71 & 2 & 3,29 & 61 & 100 & \\
\hline
\end{tabular}




\begin{tabular}{|c|c|c|c|c|c|c|c|}
\hline \multirow{3}{*}{ Pekerjaan } & \multicolumn{4}{|c|}{ Status Gizi } & \multirow{2}{*}{\multicolumn{2}{|c|}{ Jumlah }} & \multirow{3}{*}{$\rho$ value } \\
\hline & \multicolumn{2}{|c|}{ Gizi Baik } & \multicolumn{2}{|c|}{ Gizi Kurang } & & & \\
\hline & $\mathrm{n}$ & $\%$ & $\mathrm{~N}$ & $\%$ & $\mathrm{~N}$ & $\%$ & \\
\hline Bekerja & 14 & 22,95 & 0 & 0 & 9 & 22,95 & 0 \\
\hline Tidak bekerja & 45 & 73,77 & 2 & 3,27 & 47 & 77,05 & 0,001 \\
\hline Total & 59 & 96,73 & 2 & 3,27 & 61 & 100 & \\
\hline
\end{tabular}

Dari hasil uji statistik antara status gizi dengan pekerjaan ibu diperoleh $\rho$ value $=0,001$ ( $\rho$ < a 0,05), maka dapat disimpulkan bahwa ada hubungan antara pekerjaan ibu dengan kejadian gizi kurang pada balita.

\begin{tabular}{|c|c|c|c|c|c|c|c|}
\hline \multirow{3}{*}{ Paritas } & \multicolumn{4}{|c|}{ Status Gizi } & \multirow{2}{*}{\multicolumn{2}{|c|}{ Jumlah }} & \multirow{3}{*}{$\rho$ value } \\
\hline & \multicolumn{2}{|c|}{ Gizi Baik } & \multicolumn{2}{|c|}{ Gizi Kurang } & & & \\
\hline & $\mathrm{n}$ & $\%$ & $\mathrm{n}$ & $\%$ & $\mathrm{n}$ & $\%$ & \\
\hline Rendah & 58 & 95,09 & 2 & 3,27 & 60 & 98,36 & 001 \\
\hline Tinggi & 1 & 1,64 & 0 & 0 & 1 & 1,64 & 0,001 \\
\hline Total & 59 & 96,73 & 2 & 3,27 & 61 & 100 & \\
\hline
\end{tabular}

Dari hasil uji statistik antara status gizi dengan paritas ibu diperoleh $\rho$ value $=0,001(\rho<a$ $0,05)$, maka dapat disimpulkan bahwa ada

hubungan antara paritas ibu dengan kejadian gizi kurang pada balita.

\begin{tabular}{|c|c|c|c|c|c|c|c|}
\hline \multirow{3}{*}{$\begin{array}{l}\text { Asupan } \\
\text { Makanan }\end{array}$} & \multicolumn{4}{|c|}{ Status Gizi } & \multirow{2}{*}{\multicolumn{2}{|c|}{ Jumlah }} & \multirow{3}{*}{$\rho$ value } \\
\hline & \multicolumn{2}{|c|}{ Gizi Baik } & \multicolumn{2}{|c|}{ Gizi Kurang } & & & \\
\hline & $\mathrm{n}$ & $\%$ & $\mathrm{n}$ & $\%$ & $\mathrm{n}$ & $\%$ & \\
\hline Baik & 23 & 37,7 & 0 & 0 & 23 & 37,7 & 0142 \\
\hline Kurang & 36 & 59,02 & 2 & 3,28 & 38 & 62,3 & 0,142 \\
\hline Total & 59 & 96,72 & 2 & 3,28 & 61 & 100 & \\
\hline
\end{tabular}

Dari hasil uji statistik antara status gizi dengan asupan makanan diperoleh $\rho$ value $=0,142$ ( $\rho>$ a 0,05$)$, maka dapat disimpulkan bahwa tidak

ada hubungan antara asupan makanan dengan kejadian gizi kurang pada balita.

\begin{tabular}{|c|c|c|c|c|c|c|c|}
\hline \multirow{3}{*}{ Pola Makan } & \multicolumn{4}{|c|}{ Status Gizi } & \multirow{2}{*}{\multicolumn{2}{|c|}{ Jumlah }} & \multirow{3}{*}{$\rho$ value } \\
\hline & \multicolumn{2}{|c|}{ Gizi Baik } & \multicolumn{2}{|c|}{ Gizi Kurang } & & & \\
\hline & $\mathrm{n}$ & $\%$ & $\mathrm{n}$ & $\%$ & $\mathrm{n}$ & $\%$ & \\
\hline Baik & 23 & 37,7 & 0 & 0 & 23 & 37,7 & \\
\hline Kurang & 36 & 59,02 & 2 & 3,28 & 38 & 62,3 & 0,142 \\
\hline Total & 59 & 96,72 & 2 & 3,28 & 61 & 100 & \\
\hline
\end{tabular}

Dari hasil uji statistik antara status gizi dengan pola makan diperoleh $\rho$ value $=0,142(\rho>$ a 0,05), maka dapat disimpulkan bahwa tidak ada hubungan antara pola makan dengan kejadian gizi kurang pada balita.
Dari hasil uji statistik antara status gizi dengan penyakit infeksi diperoleh $\rho$ value $=0,001$ $(\rho<$ a 0,05), maka dapat disimpulkan bahwa ada hubungan antara penyakit infeksi dengan kejadian gizi kurang pada balita.

\begin{tabular}{|c|c|c|c|c|c|c|c|}
\hline \multirow{3}{*}{ Penyakit Infeksi } & \multicolumn{4}{|c|}{ Status Gizi } & \multirow{2}{*}{\multicolumn{2}{|c|}{ Jumlah }} & \multirow{3}{*}{$\rho$ value } \\
\hline & \multicolumn{2}{|c|}{ Gizi Baik } & \multicolumn{2}{|c|}{ Gizi Kurang } & & & \\
\hline & $n$ & $\%$ & $\mathrm{n}$ & $\%$ & $\mathrm{n}$ & $\%$ & \\
\hline Ada & 34 & 55,74 & 1 & 1,64 & 35 & 57,38 & \multirow{2}{*}{0,001} \\
\hline Tidak ada & 25 & 40,98 & 1 & 1,64 & 26 & 42,62 & \\
\hline Total & 59 & 96,72 & 2 & 3,28 & 61 & 100 & \\
\hline
\end{tabular}




\begin{tabular}{cccccccc}
\hline \multirow{2}{*}{ Kondisi Kamar } & \multicolumn{4}{c}{ Status Gizi } & \multicolumn{2}{c}{ Jumlah } & \multirow{2}{*}{$\rho$ value } \\
\cline { 2 - 6 } & \multicolumn{3}{c}{ Gizi Baik } & \multicolumn{2}{c}{ Gizi Kurang } & & \\
\cline { 2 - 7 } & $\mathrm{n}$ & $\%$ & $\mathrm{n}$ & $\%$ & $\mathrm{n}$ & $\%$ & \\
\hline Baik & 47 & 77,05 & 1 & 1,64 & 48 & 78,69 & \multirow{2}{*}{0,017} \\
Kurang & 12 & 19,67 & 1 & 1,64 & 13 & 21,31 & \\
\hline Total & 59 & 96,72 & 2 & 3,28 & 61 & 100 & \\
\hline
\end{tabular}

Dari hasil uji statistik antara status gizi dengan kondisi kamar mandi diperoleh $\rho$ value = $0,017(\rho>a) 0,05)$, maka dapat disimpulkan bahwa tidak ada hubungan antara kondisi kamar tidur dengan kejadian gizi kurang pada balita.

\begin{tabular}{|c|c|c|c|c|c|c|c|}
\hline \multirow{3}{*}{$\begin{array}{l}\text { Lingkungan Asap } \\
\text { Rokok }\end{array}$} & \multicolumn{4}{|c|}{ Status Gizi } & \multirow{2}{*}{\multicolumn{2}{|c|}{ Jumlah }} & \multirow{3}{*}{$\rho$ value } \\
\hline & \multicolumn{2}{|c|}{ Gizi Baik } & \multicolumn{2}{|c|}{ Gizi Kurang } & & & \\
\hline & $\mathrm{n}$ & $\%$ & $\mathrm{n}$ & $\%$ & $\mathrm{n}$ & $\%$ & \\
\hline Baik & 12 & 19,68 & 0 & 0 & 12 & 19,68 & \multirow{2}{*}{0,001} \\
\hline Kurang & 47 & 77,04 & 2 & 3,28 & 49 & 80,32 & \\
\hline Total & 59 & 96,72 & 2 & 3,28 & 61 & 100 & \\
\hline
\end{tabular}

Dari hasil uji statistik antara status gizi dengan lingkungn asap rokok diperoleh $\rho$ value $=$ $0,001(\rho<a 0,05)$, maka dapat disimpulkan bahwa

ada hubungan antara lingkungan asap rokok dengan kejadian gizi kurang pada balita.

\begin{tabular}{|c|c|c|c|c|c|c|c|}
\hline \multirow{3}{*}{ Sosial Ekonomi } & \multicolumn{4}{|c|}{ Status Gizi } & \multirow{2}{*}{\multicolumn{2}{|c|}{ Jumlah }} & \multirow{3}{*}{$\rho$ value } \\
\hline & \multicolumn{2}{|c|}{ Gizi Baik } & \multicolumn{2}{|c|}{ Gizi Kurang } & & & \\
\hline & $n$ & $\%$ & $\mathrm{n}$ & $\%$ & $\mathrm{n}$ & $\%$ & \\
\hline Baik & 23 & 37,7 & 1 & 1,64 & 24 & 39,34 & \multirow{2}{*}{0,001} \\
\hline Kurang & 36 & 59,02 & 1 & 1,64 & 37 & 60,66 & \\
\hline Total & 59 & 96,72 & 2 & 3,28 & 61 & 100 & \\
\hline
\end{tabular}

Dari hasil uji statistik antara status gizi dengan social ekonomi diperoleh $\rho$ value $=0,001$ $(\rho<$ a 0,05), maka dapat disimpulkan bahwa ada hubungan antara social ekonomi dengan kejadian gizi kurang pada balita.

\section{PEMBAHASAN}

Dari 61 responden presentase tertinggi dimiliki oleh kelompok responden dengan pendidikan rendah yang memiliki balita dengan gizi baik sebesar $81,96 \%$ (50 responden). Hasil uji statistik diperoleh $\rho$ value $=0,001(\rho<a 0,05)$, yang berarti ada hubungan antara pendidikan ibu dengan kejadian gizi kurang pada balita. Hasil penelitian ini sesuai dengan (Suharjo, 2003) faktor pendidikan orang tua balita yang rendah lebih banyak mengesampingkan pentingnya asupan gizi seimbang, sehingga konsumsi gizi pada balita juga akan mempunyai dampak pendidikan dalam hal ini lebih dikaitkan dengan kemampuan menyerap dan menerima informasi di bidang kesehatan. Masyarakat yang memiliki pendidikan lebih tinggi pada umumnya memiliki pengetahuan yang lebih luas, sehingga dapat mudah menyerap dan menerima informasi secara aktif berperan serta dalam mengatasi kesehatan dan keluarga.
Dari 61 responden presentase tertinggi dimiliki oleh kelompok responden yang tidak bekerja yang memiliki balita dengan gizi baik sebesar 73,77 $\%$ (45 responden). Hasil uji statistik diperoleh $\rho$ value $=0,001(\rho<a 0,05)$, yang berarti ada hubungan antara pekerjaan ibu dengan kejadian gizi kurang pada balita. Hasil penelitian ini sesuai dengan beberapa pendapat mengenai pekerjaan wanita.Kelompok ibu yang tidak bekerja dengan status social ekonomi rendah kurang memperhatikan kesehatan keluarganya, termasuk di sini tentang gizi balita.

Dari 61 responden presentase tertinggi dimiliki oleh kelompok responden dengan paritas rendah yaitu yang memiliki anak kurang dari 4 orang dengan balita gizi baik sebesar 95,09 \% (58 responden). Hasil uji statistik diperoleh $\rho$ value $=$ $0,001(\rho<a) 0,05)$, yang berarti ada hubungan antara paritas ibu dengan kejadian gizi kurang pada balita. Pada hasil penelitian ini paritas adalah jumlah anak yang pernah dilahirkan ibu.Semakin tinggi paritas ditambah dengan social ekonomi yang rendah, keluarga turut menentukan mutu makanan yang disiapkan.

Dari 61 responden mayoritas dengan presentase tertinggi dimiliki oleh kelompok 
responden dengan gizi balita baik yang memiliki balita dengan penyakit infeksi sebesar $55,74 \%$ (34 responden). Hasil uji statistik diperoleh $\rho$ value $=$ $0,001$ ( $\rho<$ a 0,05$)$, yang berarti ada hubungan antara penyakit infeksi balita dengan kejadian gizi kurang pada balita. Hasil penelitian ini sesuai dengan (Suryanah, 1995). Sanitasi lingkungan erat kaitannya dengan status gizi seseorang apabila kebersihan lingkungan buruk seseorang dapat dengan mudah menderita penyakit infeksi antara lain diare, saluran pernafasan (ISPA).

Dari 61 responden presentase tertinggi dimiliki oleh kelompok balita yang memiliki kondisi kamar tidur baik dengan gizi yang baik sebesar $77,05 \%$ (47 responden). Hasil uji statistik diperoleh $\rho$ value $=0,05(\rho \leq a \quad 0,05)$, yang berarti ada hubungan antara kondisi kamar balita dengan kejadian gizi kurang pada balita. Pada penelitian ini salah satu faktor yang dapat mempengaruhi status gizi balita adalah kamar tidur, penelitain ini sesuai dimana kamar tidur yang sempit dan tidur di lantai beralaskan busa tipis, dan dengan kipas angin yang dihidupkan sepanjang malam, dapat menyebabkan anak demam, sehingga kondisi ini membuat nafsu makan anak berkurang, dan asupan gizi dan nutrisi juga berkurang dan menyebabkan berat badan anak sulit naik perbulannya.

Dari 61 responden presentase tertinggi dimiliki oleh kelompok responden yang di dalam rumahnya terdapat anggota keluarga perokok dengan gizi balita yang baik sebesar 77,04 \% (47 responden). Hasil uji statistik diperoleh $\rho$ value $=$ 0,001 ( $\rho<a 0,05$ ), yang berarti ada hubungan antara lingkungan asap rokok dengan kejadian gizi kurang pada balita. Pada penelitian ini salah satu faktor yang berpengaruh terhadap status gizi yaitu asap rokok dimana balita yang terpapar asap rokok di lingkungan rumahnya akan berdampak mengalami ISPA (Infeksi Saluran Pernafasan Akut), jika balita tersebut terkena penyakit infeksi maka akan berdampak pula pada status gizinya, yaitu mengakibatkan sulit untuk mencerna asupan nutrisi yang masuk.

Dari 61 responden mayoritas dimiliki oleh kelompok responden dari tingkat sosial ekonomi rendah dengan gizi balita yang baik sebesar $59,02 \%$ (36 responden). Hasil uji statistik diperoleh $\rho$ value $=0,001 \quad(\rho<a 0,05)$, yang berarti ada hubungan antara sosial ekonomi keluarga dengan kejadian gizi kurang pada balita.Kebutuhan pemenuhan zat gizi balita sangat berhubungan dengan tingkat social ekonomi keluarga, karena untuk memenuhi kebutuhan zat gizi tersebut diperlukan biaya penunjang, jika keluarga tidak mampu membeli makanan yang bergizi maka berakibat anggota keluarga termasuk balita hanya dapat mengkonsumsi zat makanan seadanya, sehingga dapat mengakibatkan kekurangan gizi pada balita.

Dari 61 responden presentase tertinggi dimiliki oleh kelompok responden yang berumur 1734 th yaitu yang memiliki balita dengan gizi baik sebesar $80,32 \%$ (49 responden). Hasil uji statistik diperoleh $\rho$ value $=0,068(\rho>\alpha 0,05)$, yang berarti tidak ada hubungan antara umur ibu dengan kejadian gizi kurang pada balita.Hasil penelitian ini tidak sejalan dengan teori menurut Notoatmodjo, (2005, hal 344) yang menyatakan bahwa semakin matang umur seseorang maka akan semakin mudah menerima pengetahuan.

Dari 61 responden mayoritas dengan presentase tertinggi dimiliki oleh kelompok responden dengan gizi balita baik yang memberikan asupan makanan kurang kepada balitanya sebesar $59,02 \%$ (36 responden). Hasil uji statistik diperoleh $\rho$ value $=0,142(\rho>a 0,05)$, yang berarti tidakada hubungan antara asupan makanan balita dengan kejadian gizi kurang pada balita. Berdasarkan hasil penelitian ini asupan makanan balita sangat berpengaruh terhadap status gizi balita, karena baik buruknya status gizi ditentukan oleh bervariasi dan banyaknya jenis asupan makanan yang dikonsumsi.

Dari 61 responden mayoritas dengan presentase tertinggi dimiliki oleh kelompok responden dengan gizi balita baik yang memberikan pola makan kurang kepada balitanya sebesar $59,02 \%$ (36 responden). Hasil uji statistik diperoleh $\rho$ value $=0,142(\rho>a 0,05)$, yang berarti tidakada hubungan antara pola makan balita dengan kejadian gizi kurang pada balita.Pola makan yang teratur yaitu tiga kali makan dalam sehari akan membantu metabolism tubuh dan menunjang aktivitas. Jika pola makan yang tidak teratur berakibat pada gangguan penyerapan zat gizi dalam tubuh, jika mengalami kekurangan zat gizi maka tubuh akan mengambil zat dari bagian tubuh lain, sehingga penderita akan semakin terlihat kurus dan menjadi kekurangan gizi.

\section{SIMPULAN}

Faktor umur tidak memiliki hubungan yang bermakna dengan kejadian gizi kurang pada balita, dengan hasil uji statistik diperoleh $\rho$ value $=0,068$ $(\rho>$ a 0,05$)$. Faktor tingkat pendidikan ibu ada hubungan yang bermakna dengan kejadian gizi kurang pada balita, dengan hasil uji statistik diperoleh $\rho$ value $=0,001(\rho<a \quad 0,05)$. Faktor pekerjaan ibu memiliki hubungan yang bermakna dengan kejadian gizi kurang pada balita, dengan hasil uji statistik diperoleh $\rho$ value $=0,001(\rho<a$ 0,05 ).Untuk itu disarankan agar diadakan penyuluhan-penyuluhan kesehatan di tempat- 
tempat kerja baik melalui penyuluhan lewat media maupun non media. Faktor paritas ibu memiliki hubungan yang bermakna dengan kejadian gizi kurang pada balita, dengan hasil uji statistik diperoleh $\rho$ value $=0,001(\rho<a 0,05)$. Faktor penyakit infeksi memiliki hubungan yang bermakna dengan kejadian gizi kurang pada balita, dengan hasil uji statistik diperoleh $\rho$ value $=0,001(\rho<a$ $0,05)$. Faktor kondisi kamar balita memiliki hubungan yang bermakna dengan kejadian gizi kurang pada balita, dengan hasil uji statistik diperoleh $\rho$ value $=0,05(\rho \leq a 0,05)$. Faktor lingkungan asap rokok memiliki hubungan yang bermakna dengan kejadian gizi kurang, dengan hasil uji statistik diperoleh $\rho$ value $=0,001(\rho<a$ $0,05)$. Faktor pola makan balita tidak ada hubungan dengan kejadian gizi kurang pada balita, dengan hasil uji statistik diperoleh $\rho$ value $=0,142(\rho<a$ $0,05)$. Faktor asupan makan balita tidak ada hubungan dengan kejadian gizi kurang pada balita, dengan hasil uji statistik diperoleh $\rho$ value $=0,142$ $(\rho<a \quad 0,05)$. Faktor social ekonomi memiliki hubungan yang bermakna dengan kejadian gizi kurang pada balita, dengan hasil uji statistik diperoleh $\rho$ value $=0,001(\rho<a 0,05)$.

\section{SARAN}

Diharapkan kepada petugas kesehatan khususnya bidan yang menjadi kunci peningkatan pengetahuan ibu untuk bisa menambahkan frekuensi bertemu dengan para ibu agar bisa berbagi informasi khususnya mengenai gizi seimbang pada balita. Diharapkan kader-kader di posyandu dapat mengikuti pelatihan gizi seimbang dan bisa menghimbau kepada ibu-ibu agar bisa memberikan gizi seimbang kepada balitanya. Dapat melakukan penelitian dengan variable-variabel yang lebih banyak misalnya promosi dan penyuluhan tenaga kesehatan.

\section{DAFTAR PUSTAKA}

Almatsier, S. (2005). Prinsip Dasar Ilmu Gizi. Jakarta: PT Gramedia Pustaka Utama.

Asmuliyati. (2005). Faktor - faktor yang berhubungan dengan status gizi anak balita umur 12-36 bulan di desa patikarya kecamatan bantasikuyu kabupaten selayar. Makassar: STIK Tamalatea.

Bungin, B. (2006). Metode Penelitian Kualitatif. Jakarta: Kencana.

Depkes RI. (2001). Tabel Buku Rujukan Penilaian Status Gizi Anak Perempuan dan Laki-laki Menurut Berat Badan (BB/U). Jakarta: Depkes RI.

Depkes; Depsos. (2000). Kesediaan Bahan Makanan di Rumah Tangga. Jakarta: Depkes.

Harjono. (2000). Status Pekerjaan adalah Bekerja dan Tidak Bekerja. Jakarta.

Kusumah. (2007). Panduan Diet ala Rasulullah. Jakarta: Qultum Media.

Mirzawati, I. (2008). Hubungan Antara Pola Makan dan Status Gizi Anak balita di Desa Bulaksari Kecamatan Sragi Kabupaten Pekalongan.

Moejhi. (2003). Pengetahuan Dasar IImu Gizi. Jakarta: Gramedia.

Santoso, S., \& Ranti, A. L. (2004). Kesehatan dan Gizi. Jakarta: Rineke Cipta.

Suhadjo. (2003). Berbagai Cara Pendidikan Gizi. Jakarta: Bumi Aksara. 